\title{
REVISÃO CONSTITUCIONAL: LEGALIDADE E LEGITIMIDADE
}

\author{
Angela Limongi Alvarenga Alves*
}

\begin{abstract}
Sumário: Resumo. Abstract. Introdução. As propostas de emenda à constituição convocadoras de assembleias revisionais. Legitimidade da constituição de 1988. (In)constitucionalidade. (I)legalidade e (i)legitimidade. Considerações finais. Referências.
\end{abstract}

- RESUMO: O presente artigo pretende analisar as possibilidades de revisão constitucional pretendidas através de emendas constitucionais convocadoras de assembleias de revisão que tramitam no Congresso Nacional, à luz da legalidade e da legitimidade. Todas as considerações tecidas ao longo do texto tomarão a revisão pretendida em contraponto com a legalidade em seus aspectos formais - poder constituinte originário e derivado, e materiais: direitos sociais como fundamentais, frente à legitimidade. Para tanto, considerar-se-ão os postulados do processo legislativo democrático, consentâneo salutar do Estado Democrático de Direito.

- PAlAVRAS-CHAVE: Revisão constitucional. Constituição Federal de 1988. Processo Legislativo. Legalidade. Legitimidade. Democracia.

- ABSTRACT: This article will analyze at least the possibility of constitutional change sought through constitutional amendments called by assemblies of review that debated by Congress, in the light of legality and legitimacy. All points made throughout the text take the desired revision, against the legality of its formal aspects - primary and secondary constituent power, and materials: how fundamental social rights, in front of legitimacy. To this end, shall consider the postulates of the democratic legislative process, in keeping healthy democratic rule of law.

- KEY WORDS: Revision of the Constitution. 1988 Federal Constitution. Legislative Process. Legality. Legitimacy. Democracy.

\section{INTRODUÇÃO}

As tentativas de revisão constitucional não são novidade no cenário nacional. A Proposta de Emenda à Constituição (PEC) de n ${ }^{\circ}$ 157/2003 nãoé a primeira a pretender a revisão da Constituição de 1988. Antes dela, a PEC 554/1997 já pretendia convocar uma Assembleia Nacional Revisora, com trabalhos no ano de 1999. Mais recentemente, foi proposta a PEC 341/2009, pretendendo o mesmo mister. Em trâmite regular no Congresso Nacional, todas obtiveram parecer favorável da Comissão de Constituição e Justiça e de Cidadania.

Tal desiderato pode contaminar o espírito democrático do qual a Constituição de 1988 é revestida, execrando garantias fundamentais e solapando o paradigma de Estado de Direito. Sob pretenso argumento de falta de governabilidade ante a uma Constituição eclética e analítica ${ }^{1}$, o que se pretende é a supressão de direitos e a sua realocação infraconstitucional.

\footnotetext{
*Aluna dos Programas de Pós-graduação da Universidade Federal de Lavras/MG e Faculdade de Direito do Sul de Minas, Pouso Alegre/MG, Área de Concentração: Constitucionalismo e Democracia. Especialista em Direito Público pela PUC/MG. Professora e advogada. E-mail: angelalimongi2005@hotmail.com.

${ }^{1}$ Diz-se eclética a Constituição de 1988 porquanto formada por ideologias conciliatórias e analítica por abarcar assuntos diversos, considerados como fundamentais, razão pela qual não raro há necessidade de alteração para atender às mutações sociais.
} 
Apesar disso, essas propostas encontram ferrenhos entusiastas e com a mesma profundidade, veementes críticas. Porém, não há como negar a sua magnitude, bem como a pertinência dos debates acerca da questão.

Nesse sentido, para que se possa adentrar nos meandros da almejada reforma, analisaremos as propostas de emenda à luz da legalidade e qual papel desempenhado por elas quanto à legitimidade da reforma empreendida, com vistas na construção de um real Estado Democrático de Direito.

\section{ASPROPOSTASDE EIMENDAÀ CONSTTTUIÇÃOCONVOCADORASDE ASSEIMBLEIAS REVISIONAIS}

A Proposta de Emenda à Constituição de ${ }^{\circ}$ 554/1997, apresentada pelo Deputado Federal Miro Teixeira, do PDT-RJ, pretende a convocação de Assembleia Nacional de Revisão para alterações pertinentes a direitos políticos, partidos políticos, organização do Estado, competência legislativa municipal e sistema tributário nacional, obtendo parecer favorável, por unanimidade, na Comissão de Constituição e Justiça e de Cidadania e parecer favorável na Comissão Especial. Quando de sua apresentação, tinha trabalhos previstos para o ano de $1999^{3}$.

A PEC 157/2003, apresentada pelo Deputado Federal Luís Carlos Santos, do DEM-SP, pretende também convocar uma Assembleia Nacional de Revisão, almejando profundas e substanciais alterações no texto constitucional, afetando, inclusive o sistema jurídico-político-administrativo. Quando de sua apresentação, tinha previsão dos trabalhos para o ano 2007, além da discussão das matérias em sessão unicameral, com aprovação mediante deliberação da maioria absoluta em ambas as Casas Legislativas. Na Comissão de Constituição e Justiça e de Cidadania teve como relator o Deputado Federal Michel Temer, para então sofrer algumas alterações, na tentativa de amenizar os impactos negativos da medida, propondo a inclusão dos direitos sociais junto aos prescritos no rol do artigo $60, \S 4^{\circ}$, da Constituição da República, bem como a realização de referendo popular.

Por fim, decidiu-se pelo apensamento das PECs 554/1997 e 157/2003, dada a conexão da matéria.

Já a PEC 341/2009, apresentada pelo Deputado Federal Régis Fernandes de Oliveira, do PSC-SP, pretende extrair da Constituição toda e qualquer matéria de ordem formal, extirpando fulcralmente 189 artigos. Dentre esses, há diversos comandos de caráter material erroneamente tratados como se tivessem caráter formal, como aqueles pertinentes às relações do Estado brasileiro para com a comunidade internacional, tutela do meio ambiente e até mesmo os direitos sociais. Dos 70 artigos

\footnotetext{
${ }^{3}$ BRASIL. Projeto de Emenda Constitucional no 554 de 1997. Convoca Assembleia Nacional Constituinte a partir de $1^{\circ}$ de fevereiro de 1999. Disponível em: <http://www.camara.gov.br/sileg/ prop_detalhe.asp?id=14819>. Acesso em: 28 jul 2010.

4 ___. Projeto de Emenda Constitucional no 157 de 2003. Convoca Assembleia de Revisão Constitucional e dá outras providências. Disponível em: <http://www.camara.gov.br/internet/sileg/ Prop_Detalhe.asp?id=131896 >. Acesso em: 28 jul 2010.
} 
restantes, apenas esses, segundo a proposta, seriam revestidos de materialidade e permaneceriam, porquanto dirigentes da "estrutura política do poder, as formas de seu exercício, o controle e dos direitos e garantias constitucionais" 5 .

Os defensores da revisão constitucional rechaçam o caráter analítico da Constituição, que em face do detalhismo, já exigiu diversas alterações. Reclamam o 'enxugamento' do texto constitucional, argumentando ser o excesso a maior causa da inefetividade. Além disso, justificam haver ingovernabilidade em face da atual Constituição, invocando Conrad Hesse para quem "sem prescindir das disposições puramente técnico-organizativas, a Constituição deve limitar-se, na medida do possível, a uns poucos princípios fundamentais"6.

Com efeito, se aprovadas, as propostas de revisão constitucional, que de maneira geral, pleiteiam amplas e profundas alterações, ensejarão o locupletamento de novas reformas, ante a simplificação do processo legislativo e supressão de garantias constitucionais, revestindo de discricionariedade os detentores do poder e dando cores aos atos de arbitrariedade e autoritarismo.

\section{LEGITIMIDADE DA CONSTTTUIÇÃO DE 1988}

Será a Constituição de 1988 ilegítima, de forma a ensejar ingovernabilidade, trazer em seu bojo excesso de detalhismo e fomentar profundas alterações?

Com efeito, a legitimidade da Constituição de 1988 não decorre de seu ato convocatório, tampouco é resultado do manipulado processo eleitoral que elegeu um dos Congressos mais conservadores de nossa história. Sua legitimidade decorre do inusitado processo de sua elaboração?.

A proposta de Constituição elaborada por uma comissão de notáveis juristas ${ }^{8}$ restou enfraquecida diante dos influxos de mobilização popular já arraigados no movimento das Diretas Já9 e que já amargava a frustração pela não aprovação da

\footnotetext{
${ }^{5}$ BRASIL. Projeto de Emenda Constitucional no 341 de 2009. Modifica os dispositivos constitucionais retirando do texto matéria que não é constitucional. Disponível em: < http://www.camara.gov.br/ sileg/Prop_Detalhe.asp?id=427473 > . Acesso em: 10 jul. 2010.

${ }^{6}$ HESSE, Conrad. Escritos de derecho constitucional. Madrid: Centro de Estúdios Constitucionales, 1992. p. 67. ${ }^{7}$ CARVALHO NETTO, Menelick. A urgente revisão da teoria do poder constituinte: a impossibilidade da democracia possível. In: CATTONI DE OLIVEIRA, Marcelo. Poder constituintee patriotismo constitucional: o projeto constituinte do estado democrático de direito na teoria discursiva de Jürgen Habermas. Belo Horizonte: Mandamentos, 2006. p. 24-25.

${ }^{8}$ Menelick de Carvalho Netto traz o termo "comissão de notáveis" grafado entre aspas, referindo-se à comissão de juristas responsáveis pela elaboração do projeto da Constituição de 1988. Cf. CARVALHO NETTO, Menelick. A urgente revisão da teoria do poder constituinte: a impossibilidade da democracia possível. In: CATTONIDE OLIVEIRA, Marcelo. Poder constituintee patriotismo constitucional: o projeto constituinte do estado democrático de direito na teoria discursiva de Jürgen Habermas. Belo Horizonte: Mandamentos, 2006. p. 25.

${ }^{9}$ Diretas Já foi um movimento civil de reivindicação por eleições presidenciais diretas no Brasil ocorrido em 1983-1984. A ossibilidade de eleições diretas para a Presidência da República no Brasil se concretizou com a votação da proposta de Emenda Constitucional Dante de Oliveira pelo Congresso. Entretanto, a Proposta de Emenda Constitucional foi rejeitada, frustrando a sociedade brasileira. Ainda assim, os adeptos do movimento conquistaram uma vitória parcial em janeiro do ano seguinte
} 
Emenda Dante de Oliveira ${ }^{10}$ e o falecimento de Tancredo Neves, ícone da transição para a democracia, o que acabou exigindo a reformulação do procedimento iniciado e a consequente abertura democrática do processo constituinte ${ }^{11}$ :

Estas forças populares mobilizadas acompanharam o processo de elaboração da Constituição, enviando sugestões, debatendo na imprensa, pressionando os constituintes, ações estas que resultaram em uma 'participativa metodologia de montagem do anteprojeto a partir da coleta de sugestões populares', caracterizando-se assim pela redação de uma Constituição resultante 'de uma autêntica manifestação do poder constituinte, em razão do processo adotado'. ${ }^{12}$

Em razão disso, paradoxalmente, a Constituinte de 1988 era composta por uma das legislaturas mais conservadoras que o Brasil já teve e elaborou a Constituição mais progressista de nossa história. E é justamente da abertura democrática que a sua legitimidade é decorrente:

\begin{abstract}
A legitimidade da Constituição de 1988 advém do seu processo de elaboração democrático, aberto e participativo, processo esse que, deve ser condição de legitimidade para qualquer alteração mais ampla que venha a se sujeitar a Constituição, algo que infelizmente não ocorreu nem mesmo na revisão de 1993 (realizada de forma apressada e irregular). Assim é que para o autor [Marcelo Andrade
\end{abstract}

quando um de seus líderes, Tancredo Neves, foi eleito presidente pelo Colégio Eleitoral. Disponível em: < http://pt.wikipedia.org/wiki/Diretas_J\%C3\%A1>. Acesso em 01 de ago de 2010.

${ }^{10}$ Recebeu o nome de emenda Dante de Oliveira a proposta de emenda constitucional (PEC n5/ 1983) formulado pelo deputado federalDante de Oliveira (PMDB-MT) em 1984 que tinha por objetivo reinstaurar as eleições diretas para presidente da República no Brasil, uma vez que a tradição democrática havia sido interrompida no país pelo golpe militar de 1964. A enorme pressão popular para que a emenda fosse aprovada transformou-se num dos maiores movimentos políticosociais da história do Brasil e logo recebeu o nome de Diretas Já. De acordo com uma pesquisa do IBOPE, $84 \%$ da população brasileira era favorável à aprovação da emenda. Apesar do alarido popular, a emenda constitucional foi rejeitada pela Câmara dos Deputados no dia 25 de abril de 1984. Por se tratar de uma emenda constitucional, precisava dos votos de dois terços da Casa (320 deputados) para prosseguir ao Senado. O resultado da votação foi o seguinte: 298 deputados votaram a favor, 65 contra, três abstiveram-se e 113 não compareceram ao plenário. Com a rejeição da emenda, a eleição para presidente da República de 1985 foi novamente indireta. Entretanto, articulações da oposição ao regime militar, em especial do PMDB, endossadas pela mídia e com forte apoio popular, racharam a base governista que era maioria no Congresso Nacional, ocasionando a escolha do oposicionista Tancredo Neves (PMDB) como presidente da República. Encerrou-se assim um ciclo de cinco presidentes militares iniciado em 1964. Tacredo porém, nunca viria a tomar posse, falecendo por sérios problemas de saúde no dia 21 de abril de 1985. Seu vice, José Sarney, tomou posse em 15 de março daquele mesmo ano, sendo também um dos responsáveis pelo processo de redemocratização do país, mesmo tendo apoiado os militares por vinte anos. Disponível em: <http://pt.wikipedia.org/wiki/Emenda_Constitucional_Dante_de_Oliveira $>$. Acesso em 01 de ago de 2010.

${ }^{11}$ CARVALHO NETTO, Menelick. Ibidem.

${ }^{12}$ SIQUEIRA, Gustavo Silveira. Legitimidade, reforma e democracia na constituição federal de 1988. Flonianópolis: CONPEDI, 2007. 
Cattoni de Oliveira] é inquestionável a legitimidade da Constituição de $1988 .{ }^{13}$

\section{(IN)CONSTITUCIONALIDADE}

O Poder Constituinte Derivado ou Poder de Emenda é lídimo responsável pelas alterações - emendas ou revisão ${ }^{14}$ - em face do texto constitucional exarado pelo Poder Constituinte Originário. A competência para tal desiderato foi conferida pela própria Constituição, ao Congresso Nacional.

Entretanto, o poder de reforma é limitado, devendo ater-se aos limites e formas fixados pelo Poder Constituinte Originário, sem olvidar dos parâmetros de ordem formal, material, temporal e circunstancial.

Ademais, as limitações ao Poder de Reforma dividem-se em explícitas e implícitas. As limitações formais explícitas dizem respeito à forma a ser obedecida, o procedimento para instituição de emendas e/ou revisão, enquanto as materiais explícitas consubstanciam-se em cláusulas pétreas explícitas, insculpidas, especialmente, no artigo 60 , $4^{\circ}$ e seus incisos, da Constituição.

A doutrina aponta, contudo, limitações implícitas ao Poder Reformador. São as denominadas cláusulas pétreas implícitas: "as concernentes ao titular do poder constituinte" ${ }^{15}$, pois uma reforma constitucional não pode alterar o titular do poder que cria o próprio poder reformador; "as referentes ao titular do poder reformador"16,

\footnotetext{
${ }^{13}$ CARVALHO NETTO, Menelick. Ibidem. Por outro lado, pontua Cattoni de Oliveira que a proposta deliberativa de Habermas teria sido rechaçada por Frank Michelman por ser incapaz de solucionar a suposta relação paradoxal entre Estado de Direito e democracia. Esse paradoxo ressurgiria todas as vezes que se tentasse identificar, de modo retrospectivo, o ato que criou uma Constituição e se se tentasse averiguar se a própria formação da opinião e da vontade daqueles que se reuniram para dar origem à Constituição poderia ser entendida como um processo democrático. A própria Assembleia Constituinte não poderia garantir a legitimidade democrática das normas com base nas quais ela mesma teria sido constituída, o "processo democrático cairia em um regresso ao infinito", pelo "caminho de autoconstituição circular". Cf. CATTONI DE OLIVEIRA, Marcelo. Poder constituintee patriotismo constitucional: o projeto constituinte do estado democrático de direito na teoria discursiva de Jürgen Habermas. Belo Horizonte: Mandamentos, 2006. p. 35-36.

${ }^{14}$ Pertinenteassinalar: "Emendaerevisão constitucionaissãoespécies do gêneroreforma constitucional. Tecnicamente, distinguem-se.Diz-seemendaconstitucionalorecursoinstituídopelopoderconstituinteoriginániopararealizarmodificaçóesem pontosespećificoselocalizadosdotextomaior.Jáarevisãoconstitucional quetambéméumrecursoinstitúdopelopoderconstituinte originário, objetiva mudar a constituiçãoamplamente. A Cartade 1988enunciouambasastécnicas dealteraçãoformaldas constituiçõesdemaneirapromíscua, sem tecermaioresdetalhamentosdeumaou deoutra. Previu,noart.60, aemenda,e,noart. $3^{\circ}$ das Disposicões Transitónias, arevisão. Pelaformulaçãodogmáticadoconstituinteoriginánio, aemendaéumdosatosnormativos integrantesdoprocessolegislativo, oquenãose dácomarevisão(art. 59).Sejacomofor, apalavraemenda, empregadanoart.60, significareforma demenor extensão. Jáarevisão, nostermos doart. $3^{\circ} \mathrm{do} A D C T$, equivalea umareforma demaior amplitude. Assim, enquantoaemendaserveparamudartópicosdaconstituição, a revisãoobjetivaalterargamamaiordematérias.Naprática, tudoqueacabamos de dizernãoélevadoem conta, principalmenteno Brasil. Aquise deturpatudo. Cite-secomoexemploa frustrada revisãoconstitucional de 1994, conclusa com, apenas, seismodificaçõesformaisnotexto primitivo da Constituição vigente.Emcontrapartida, saliente-seoexcessivonúmerodeemendasconstitucionais, atingindoatudoeatodos, irrestritamente. Aliás,nesse particular, a histónia pátriaépródigaem teratologias. Muitossãoosexemplos deemendasconstitucionaisquese transformaramemautênticasrevisões constitucionais. Arecíprocaéverdadeira". Cf. BULOS, UadiLammêgo. Cursode direito constitucional. 4 ed. São Paulo: Saraiva, 2009. p. 296.

${ }^{15}$ SILVA, José Afonso da. Curso de direito constitucional positivo. 22 ed. São Paulo: Malheiros, 2002.

${ }^{16}$ Ibidem.
} 
pois seria despropositado que o legislador ordinário estabelecesse novo titular de um poder derivado só da vontade do constituinte originário; "as relativas ao processo da própria emenda" ${ }^{17}$, distinguindo-se quanto à natureza da reforma, para admiti-la quando se tratar de tornar mais difícil seu processo, não a aceitando quando vise a atenuá-lo ${ }^{18}$.

Assim, forçoso é reconhecer que qualquer tipo de reforma tendente a modificar o procedimento de emenda à Constituição (limitação formal) ou mesmo a modificar o titular do Poder Constituinte (limitação material), criando, vale dizer, situações não esposadas pelo Poder Constituinte Originário, usufruindo de poderes que outrora não lhe foram concedidos, estará colocando em xeque a constitucionalidade, podendo ferir cláusulas pétreas implícitas na Constituição.

Em que pesem os argumentos contrários, a ampla discussão sobre o tema é imprescindível para o Estado Democrático de Direito.

A uma porque as PECs almejam criar na Ordem Constitucional um novo quorum para a sua aprovação, que será o de maioria absoluta em cada Casa Legislativa, com votações separadas, que deverá passar por dois turnos de discussão e de votação, sendo que a discussão das propostas será realizada em sessão unicameral, alterando, outrossim, a limitação formal explícita traçada pelo artigo 60 do texto constitucional de 1988:

\begin{abstract}
É preciso deixar claro que a PEC 157, que visa à redução do quorum de três quintos para maioria absoluta, à diminuição dos turnos de votação, bem como à reunião unicameral das Casas Legislativas, enfim, a uma simplificação do processo legislativo de reforma, é inconstitucional, estando sujeita à declaração de inconstitucionalidade pelo Poder Judiciário. Tão inconstitucional que o porteiro do STF deveria declará-la, dispensando-se os Ministros da Corte de apreciar tamanha heresia. ${ }^{19}$
\end{abstract}

A dois porque a revisão constitucional prevista pelo Poder Constituinte Originário possui eficácia exaurida ${ }^{20}$, já que fora realizada em 1993, sendo, portanto, vedada a criação de uma nova Assembleia Constituinte Revisional:

Ora, é preciso entender que só se pode convocar uma Constituinte na hipótese de ruptura institucional, que deve ser grave, com as instituições inviabilizadas, povo na rua, economia em crise, etc. Não se dissolve um regime democrático porque se quer

\footnotetext{
17 Ibidem.

${ }^{18}$ RAMOS, William Junqueira. Ainconstitucionalidade doprojeto deemenda àconstituiçãofederal (pec) $n^{\circ}$ 157/03, que convoca uma nova assembléia constituinte revisional. Disponível em <http://jus2.uol.com.br/doutrina/ texto.aps?id=8093>. Acesso em 03 de jun de 2010.

${ }^{19}$ STRECK, Lênio Luiz; CATTONI DE OLIVEIRA, Marcelo Andrade; CARVALHO NETTO, Menelick de; LIMA, Martonio Barreto. Revisãoégolpe! Porque ser contra a proposta de revisão constitucional. Disponívelem: $<$ http://jus2.uol.com.br/doutrina/texto.aps?id=8093> Acesso em 28 junho 2010.

${ }^{20}$ BULOS, Uadi Lammêgo. Curso de direito constitucional. 4 ed. São Paulo: Saraiva, 2009.
} 


\begin{abstract}
fazer outro (como seria esse 'outro'?). A Constituição é coisa séria, fruto de uma repactuação ('We the People...'). E nela colocamos cláusulas pétreas e forma especial de elaborar emendas. Portanto, alto lá! Não se pode fazer política e vender falsas ilusões em cima daquilo que é a substância das democracias contemporâneas: o constitucionalismo. ${ }^{21}$
\end{abstract}

Nas PECs 554/97 e 157/03, com exceção dos direitos sociais previstos nos artigos $6^{\circ}$ a 11 , bem como das cláusulas pétreas descritas no artigo $60, \S 4^{\circ}$ e seus incisos, da Constituição da República, tudo mais poderá ser alterado. Já quanto a PEC 341/2009, nem há essa limitação. Absolutamente tudo poderá ser alterado.

Em que pese a tentativa de minorar os nefastos efeitos das PECs 554/1997e 157/2003 ante a realização de referendo popular, é interessante assinalar que "plebiscitos e referendos foram instrumentos utilizados com freqüência como meio de manipulação pública pelas piores ditaduras, o que nos revela que a participação direta, por si só, não é qualquer garantia"22.

E é de primacial importância pontuar que o controle de constitucionalidade preventivo transcorre pela constitucionalidade das propostas, haja vista os pareceres favoráveis das Comissões de Constituição e Justiça e de Cidadania. Paralelamente, observe-se que o Estado brasileiro tem legislado sobre o controle de constitucionalidade a partir da perspectiva perlocucionária de uma ação estratégica ${ }^{23}$, pelo que o controle repressivo a bem das vezes é sobrepujado pelos interesses dos detentores do poder ${ }^{24}$. Ademais, o comportamento do Supremo Tribunal

${ }^{21}$ STRECK, Lênio Luiz. Assembleia constituinte é golpe! Última instância. Porto Alegre, sexta-feira, 19 de ago. 2005. Disponível em: <http://www.leniostreck.com.br>. Acesso em 09 de ago de 2010.

${ }^{22}$ CARVALHO NETTO, Menelick. A urgente revisão da teoria do poder constituinte: a impossibilidade da democracia possível. In: CATTONIDE OLIVEIRA, Marcelo. Poder constituintee patriotismo constitucional: o projeto constituinte do estado democrático de direito na teoria discursiva de Jürgen Habermas. Belo Horizonte: Mandamentos, 2006. p. 24.

${ }^{23} \mathrm{CRUZ}$, Álvaro Ricardo de Souza. Breve histórico do supremo tribunal federal e do controle de constitucionalidade brasileiro. In: SAMPAIO, José Adércio Leite (Coord.) Crise e desafios da constituição: perspectivas críticas da teoria e das práticas constitucionais brasileiras. Belo Horizonte: Del Rey, 2003. p. 201-255. p. 253. Explicitao autor: "Nodesenvolvimentoda Teoria Discursiva do Direito, Habermas(1997)importa deAustin (1990, p. 21)a concepçãodeaçãoperformativa, istoé, aidéia pelaqualumatodelinguagempossamaisdoquesimplesmentecomunicaruma idéia (atolocucionário), mastambém realizarumaaçãodiferentedaprópriacomumicação(atoilocucionário). Comoexemplodesse efeitodenominadoilocução(Austin, 1990,p.2425)mencionaa expressão "aceito" pelosnubentesnumacerimôniadecasamento. Jáoconteúdoperlocucionárioseriauma '....] terceira dimensão, ou um terceirosentido, doatodelinguagem, que dizrespeitoàs conseqüênciasouaosresultadosparticulares,nãoconvencionaisdoatodelinguagem'(MAGALHÃES, Thereza Calvetde.Filosofia analitica:deWittgensteinàredescobertadamente.Cademosda PósGraduação,BeloHonizonte:MovimentoEditonialdaFaculdade deDireitodaFMG, 1997, p. 122). '[...] Aodizeraalguém: 'prometoajudá-lonamudança', estoufazendoumapromessaeaofazer issotambémpossosurpreender, agradarouassustara pessoaa quemestouprometendo ajuda. Provocar estesefeitosaose expressaréoqueAustinchamadeatoperlocucionário[...' (ALEXXY,Robert. Teoriadaargumentaçãojuńdica.Ateoniadodiscurso racionalcomoteoria dajustificaçãojuńdica. TraduçãodeZildaHutchisonSchildSilva.SãoPaulo:Landy, 2001,p. 59."

24 "UmaProposta de Emenda do tipoda PEC157, quepretendemodificarodispostonoart.60, da Constituiçãodo Brasil, viola arigidezconstitucional-enãoporumsimples apegoà forma Cabeinsistir:elaviolaa Constituiçãoporquecolocaemriscodireitos egarantias dasminoriaspolíticasemfacedosinteresses dasmaionias, porqueinfringemasprópriascondiçõesconstitucionaise processuaispara deliberaçãopormaioria, subvertendo, assim, opróprio processolegislativo democrático, soba desculpa de democracia." Cf. STRECK, Lênio Luiz; CATTONI DE OLIVEIRA, Marcelo Andrade; CARVALHO 
Federal endossa esse cenário e lhe é subserviente, coadunando com as investidas autoritárias desses grupos ${ }^{25}$.

Nesse sentido, adverte Carvalho Netto, 2003, que:

A manipulação estratégica do arcabouço constitucional é sempre possível. Na Teoria da Constituição clássica, foi exatamente para enquadrar esse tipo de embuste histórico que Karl Loewenstein, na sua classificação ontológica, criou a categoria das constituições por ele qualificadas como 'semânticas'. Essa categoria foi pensada por Loewenstein para agrupar as constituições que traíssem o sentido originariamente atribuído a essa invenção moderna, ao se instituírem e funcionarem não mais como uma garantia dos cidadãos contra eventuais ocupantes do poder institucionalizado, mas ao contrário, como uma garantia dos detentores do poder contra os cidadãos. ${ }^{26}$

E prossegue o mesmo autor:

Para a atual Teoria da Constituição, essas experiências históricas traem o próprio constitucionalismo e dele buscam abusar em proveito próprio, por isso mesmo, de modo algum podem ser consideradas experiências constitucionais. ${ }^{27}$

Por outro lado, a compreensão dos direitos sociais como direitos fundamentais é indeclinável. Na realidade, os que pretendem a sua supressão do texto constitucional aproveitam-se da carga de indeterminação metodológica ${ }^{28}$ a eles inerente:

[...] importa reconhecer que, mesmo nos estritos parâmetros jurídico-dogmáticos, os direitos sociais aparecem envoltos em quadros pictóricos, onde o envolto jurídico cede lugar a nebulosas normativas. É aqui que surge o ‘camaleão normativo' [que significa] a instabilidade e imprecisão normativa de um sistema jurídico aberto - como o dos direitos sociais - quer a conteúdos imanentes ao próprio sistema (system-immanente), quer a conteúdos normativos transcendentes (system-transcendente). Essa indeterminação normativa explicaria, em grande medida, a confusão entre conteúdo de um direito, juridicamente definido e determinado e sugestão de conteúdo, sujeita a modelações político-jurídicas cambiantes. ${ }^{29}$

NETTO,Menelickde;LIMA,Martonio Barreto.Revisãoégolpe! Porquesercontra a proposta derevisãoconstitucional. Disponível em: <http://jus2.uol.com.br/doutrina/texto.aps?id=8093> Acesso em 28 junho 2010. ${ }^{25}$ CRUZ, Álvaro Ricardo de Souza. Ibidem, p. 253.

${ }^{26}$ CARVALHO NETTO, Menelick. A constituição da europa. In: SAMPAIO, José Adércio Leite (Coord.) Crise e desafios da constituição: perspectivas críticas da teoria e das práticas constitucionais brasileiras. Belo Horizonte: Del Rey, 2003. p. 281-289. p. 283.

${ }^{27}$ Ibidem, p. 283.

${ }^{28}$ Segundo Canotilho(2008, p.99): "A nossover, pairasobrea dogmática esobrea teoriajurídica dos direitoseconômicos, sociaiseculturaisacargametodológicada vagueza', indeterminação'e impressionismo'queateoriadaciênciavemapelidando de 'fuzzysmo' ou 'metodologia fuzzy'." CANOTLHO, José Joaquim Gomes. Estudos sobre direitos fundamentais. 2 ed. Coimbra: Coimbra Editores, 2008. p. 99.

${ }^{29}$ CANOTILHO, José Joaquim Gomes. Estudos sobre direitos fundamentais. 2 ed. Coimbra: Coimbra Editores, 2008. p. 100-101. 
Em outras palavras, esse "transformismo normativo"30 dá azo à transmutação de um discurso jurídico lastreado pelos rigores de objetivação para um discurso político-constitucional carreado por programas e diretivas de agendas políticas, o que reduz os direitos sociais a conceitos normativos abertos, na freqüente "confusão entre direitos sociais e políticos e políticas públicas de direitos sociais"31.

É evidente que a mera previsão dos direitos sociais no texto constitucional não foi capaz de elidir as objeções a sua inserção nem mesmo o déficit de ineficiência desses direitos, notadamente sua (in)efetividade. Ancorados nessa indeterminação é que postulam alguns sua realocação infraconstitucional. Nesse sentido:

\begin{abstract}
Entre os temas preferidos pela doutrina (e que acabam refletindo, com maior ou menor intensidade, na esfera jurisprudencial, legislativa e administrativa) destacam-se, notadamente, em matéria dos assim chamados direitos sociais, tanto as teses que questionam a própria constitucionalização de tais direitos (sustentando até mesmo que, no todo ou em parte, tais direitos nem mesmo deveriam estar na Constituição!) quanto os clamores daqueles que, embora admitam a possibilidade de ter tais direitos previstos no texto constitucional, refutam a sua condição de autênticos direitos fundamentais. Além disso, assume particular relevância a controvérsia em torno do regime jurídico-constitucional dos direitos sociais, uma vez reconhecida a sua condição de direitos fundamentais, o que, por sua vez, remete ao problema de sua eficácia e, por conseguinte, de sua efetividade. ${ }^{32}$
\end{abstract}

Porém, como visto, a própria teoria dos direitos fundamentais sofreu também consideráveis alterações ${ }^{33}$ nos últimos anos, principalmente conquanto a sua concepção e ampliação. A uma porque se considera que os direitos fundamentais são trunfos ${ }^{34}$, não dádivas, permissivos ou garantias contra ingerências estatais, como outrora. A dois porque os direitos fundamentais devem ser compreendidos não apenas como aqueles taxativamente elencados na Constituição Federal, mas todos aqueles oriundos de legislação infraconstitucional e de tratados internacionais dos quais o Brasil seja signatário ${ }^{35}$.

A bem da verdade, os direitos sociais enquanto direitos prestacionais, reclamam erário público para sua implementação e em contra-argumento, muitas

\footnotetext{
${ }^{30}$ Ibidem.

${ }^{31}$ Ibidem.

${ }^{32}$ SARLET, Ingo Wolfgang. Direitos sociais como direitos fundamentais. In: LEITE, George Salomão; SARLET, Ingo Wofgang. (Coord.). Direitos fundamentais e estado constitucional: estudos em homenagem a J.J. Gomes Canotilho. São Paulo: RT, 2009. p. 213-253. p. 215.

${ }^{33}$ Alterações oriundas, sobretudo, da "Escola Mineira" de Direito Constitucional.

${ }^{34}$ Cf. DWORKIN, Ronald. Levando os direitos a sério. Trad. Nelson Boeira. São Paulo: Martins Fontes, 2002. Muito embora concordemos com essa assertiva, discordamos da argumentação jurídica segundo o mesmo autor.

${ }^{35}$ SARLET, Ingo Wolfgang. Direitos sociais como direitos fundamentais. In: LEITE, George Salomão; SARLET, Ingo Wofgang. (Coord.). Direitos fundamentais e estado constitucional: estudos em homenagem a J.J. Gomes Canotilho. São Paulo: RT, 2009. p. 213-253. p. 223.
} 
das vezes o próprio Estado invoca conjecturas para reforçar sua inefetividade, haja vista a ferrenha defesa pela reserva do possível.

Inobstante, é primacial pontuar que:

A Constituição canaliza e viabiliza a democracia, mas se se espera que ela, unicamente por suas normas, possa substituir, apenas a título de exemplo, o tratamento político dos problemas políticos e o cuidado econômico das questões econômicas por imperativos constitucionais cogentes que dispensem o jogo democrático e a condução concreta de políticas econômicas e sociais, terminar-se-á por pagar o preço do incremento da desestima constitucional a corroer toda a sua potencial força normativa e a gerar a ineficácia de suas normas, produzindo, na prática, efeitos opostos aos almejados. ${ }^{36}$

\section{(I)LEGALIDADE E (I)LEGITIMIDADE}

Nesta esteira, é pertinente trazer à baila a problemática relação cidadão Parlamento no que tange aos influxos democráticos, e, da constatação de que o Parlamento está ensurdecido em relação a esses influxos ${ }^{37}$. Com efeito, toda e qualquer deliberação legislativa carece de amplos debates, de forma a concretizar um modelo de eclusas ${ }^{38}$, no qual o Parlamento se abre aos influxos da periferia e delibera com liberdade de atuação. Entretanto, o que se vislumbra, mais uma vez, é a ausência de ampla participação democrática quanto à tramitação dessas propostas de revisão constitucional, caracterizando a colonização ${ }^{39}$ do processo legislativo pelos defendentes de políticas neoliberais, tendenciosos a desconstitucionalizar direitos, sobretudo os sociais.

Uma norma só é aceita positivamente quando ela se reveste de um procedimento juridicamente válido. A validade social das normas do direito é determinada pelo seu grau de imposição, ao passo que a legitimidade das normas jurídicas se mede pela resgatabilidade discursiva de sua pretensão de validade normativa:

A validade social de normas do direito é determinada pelo grau em que consegue se impor, ou seja, pela sua possível aceitação fática no círculo dos membros do direito. Ao contrário da validade convencional dos usos e costumes, o direito normatizado não

${ }^{36}$ CARVALHO NETTO, Menelick. A constituição da europa. In: SAMPAIO, José Adércio Leite (Coord.) Crise e desafios da constituição: perspectivas críticas da teoria e das práticas constitucionais brasileiras. Belo Horizonte: Del Rey, 2003. p. 281-289. p. 282.

${ }^{37}$ HABERMAS, Jürgen. A constelação pós-constitucional: ensaios políticos. Trad. Márcio Seligmann-Silva. São Paulo: Littera Mundi, 2001.

${ }^{38}$ Ibidem.

${ }^{39}$ Ibidem. Segundo a proposta de Habermas, no modelo de sitiamento o Parlamento não possui autonomia, sendo tomado por interesses de certos grupos, caracterizando a colonização do processo legislativo. 


\begin{abstract}
se apóia sobre a facticidade de formas de vida consuetudinárias e tradicionais, e sim sobre a facticidade artificial da ameaça de sanções definidas conforme o direito e que podem ser impostas pelo tribunal. Ao passo que a legitimidade de regras se mede pela resgatabilidade discursiva de sua pretensão normativa; e o que conta, em última instância, é o fato de que elas poderiam ter sido justificadas sob pontos de vista pragmáticos, éticos e morais. A legitimidade de uma regra independe do fato de ela conseguir impor-se. Ao contrário, tanto a validade social, como a obediência fática, variam de acordo com a fé dos membros da comunidade de direito na legitimidade, e esta fé, por sua vez, apóia-se na suposição da legitimidade, isto é, na fundamentabilidade das respectivas normas. ${ }^{40}$
\end{abstract}

A norma torna-se jurídica no momento que ela é elaborada por um procedimento jurídico e tem validade social quando ela é aceita de fato pelos afetados por essa norma - quando os cidadãos a aceitam, e, se legitima apenas quando o seu conteúdo provém da discussão social ${ }^{41}$.

Nesse sentido, é possível diferenciar legalidade e legitimidade: a legitimidade de uma norma independe do fato de sua imposição no meio social, e o direito positivado corre o risco de perder seu poder de integração social se a legalidade não for norteada pela legitimidade ${ }^{42}$.

Na realidade, a criação democrática do direito constitui a única fonte pósmetafísica de legitimidade, no sentido proposto por Jürgen Habermas:

Onde se fundamenta a legitimidade de regras que podem ser modificadas a qualquer momento pelo legislador político? Esta pergunta torna-se angustiante em sociedades pluralistas [como a nossa], nas quais as próprias éticas coletivamente impositivas e as cosmovisões se desintegram e onde a moral pós-tradicional da consciência, que entrou em seu lugar, não oferece mais uma base capaz de substituir o direito natural, antes fundado na religião e na metafísica. Ora, o processo democrático da criação do direito constitui a única fonte pós-metafísica da legitimidade. No entanto, é preciso saber de onde ele tira sua força legitimadora. A teoria do discurso fornece uma resposta simples, porém inverossímil à primeira vista: o processo democrático, que possibilita a livre flutuação de temas e de contribuições, de informações e de argumentos, assegura um caráter discursivo à formação política da vontade, fundamentando, desse modo, a suposição falibilista de que os resultados obtidos de acordo com esse procedimento são mais ou menos racionais. [...] Do ponto de vista da teoria do direito, as ordens jurídicas modernas extraem sua legitimação da idéia de autodeterminação, pois as pessoas

${ }^{40}$ HABERMAS, Jürgen. Direito e democracia: entre facticidade e validade. Trad. de Flávio Bueno Siebneichler. Rio de Janeiro: Tempo Brasileiro, 1997, p. 50.

${ }^{41}$ Ibidem.

${ }^{42}$ Ibidem. 
devem poder se entender a qualquer momento como autoras do direito, ao qual estão submetidas como destinatários. ${ }^{43}$

O processo legislativo deve a sua legitimidade a um tipo de reconhecimento que é baseado em um acordo motivado racionalmente. Essa suposição é estabelecida nos termos do discurso: "são válidas aquelas normas com as quais todas as pessoas possivelmente afetadas podem concordar enquanto participantes de discursos racionais." ${ }^{44}$

Para tanto, é imprescindível que haja ampla participação popular, de forma a garantir uma efetiva estância democrática pelo envolvimento dos sujeitos, onde 0 foco esteja voltado para o debate, conquanto os indivíduos considerem-se autores e destinatários do seu próprio direito, afinal a intersubjetividade é o locus em que o paradigma do Estado Democrático de Direito se assenta.

\begin{abstract}
Ademais, o status democrático é exigente nesse sentido: Esta é, afinal, a regra do jogo democrático e o custo que representa viver sob a égide do Estado Democrático de Direito. E é dessa intrincada engenharia política que exurge um novo papel para o direito, e por conseqüência, para a Constituição (... $)^{45}$.
\end{abstract}

\title{
CONSIDERAÇÕES FINAIS
}

O presente artigo pretendeu uma reflexão sobre as (im)possibilidades de revisão constitucional e as consequências deflagradas para o regime democrático, sobretudo no que pertine à legitimidade das alterações pretendidas.

Nesse sentido, defende-se os direitos sociais como direitos fundamentais e o entendimento de sua inserção no rol prescrito pelo artigo 60 , $4^{\circ}$, da Constituição da República.

Demais disso, pugna-se por maior acuidade no que tange às pretendidas reformas constitucionais, razão pela qual se defende a ampla participação popular com vistas aos influxos democráticos de forma a efetivar o processo legislativo comparticipativo ${ }^{46}$ como consentâneo do Estado de Direito.

\footnotetext{
${ }^{43}$ HABERMAS, Jürgen. Direito e democracia: entre facticidade e validade. Trad. de Flávio Bueno Siebneichler. Rio de Janeiro: Tempo Brasileiro, 1997. p. 308-309.

44 . Between facts and norms: contributions to a discourse theory of law and democracy. Trad. William Rehg. Cambridge: MIT Press, 1996. p. 107.

${ }^{45}$ STRECK, LenioLuiz. Umaabordagemhermenêuticaacerca dotriângulodialético decanotilhoou decomoaindaéválida a tese da constituição dirigente (adequada a países demodemidade tardia. In: LEITE, George Salomão; SARLET, Ingo Wofgang. (Coord.). Direitos fundamentais e estado constitucional: estudos em homenagem a J.J. Gomes Canotilho. São Paulo: RT, 2009. p. 50-78. p. 74. Nesse sentido: "O processo democrático carrega ofardo dalegitimação. Poistemqueassegurarsimultaneamenteaautonomiaprivadaepúblicadossujeitos dedireito; eparaformular adequadamenteosdireitosprivadossubjetivosouparaimpô-lospoliticamente, énecessárioqueosafetadostenhamesclarecido antes, em discussóespúblicas, ospontos devista relevantespara otratamentoigualounão-igualdecasos típicosetenham mobilizadoo poder comunicativo para a consideraçãode suasnecessidadesinterpretadas demodonovo." HABERMAS, Jürgen. Direito e democracia: entre facticidade e validade. Trad. de Flávio Bueno Siebneichler. Rio de Janeiro: Tempo Brasileiro, 1997. p. 310.

${ }^{46}$ Cf. NUNES, Dierle José Coelho. Processo constitucional democrático. Curitiba: Juruá, 2008.
} 


\section{REFERÊNCIAS}

BRASIL. Projeto de Emenda Constitucional n 554 de 1997. Convoca Assembleia Nacional Constituinte a partir de $1^{\circ}$ de fevereiro de 1999. Disponível em: <http:// www.camara.gov.br/sileg/prop_detalhe.asp?id=14819>. Acesso em: 28 jul 2010.

Projeto de Emenda Constitucional no 157 de 2003. Convoca Assembleia de Revisão Constitucional e dá outras providências. Disponível em: <http://www.camara.gov.br/ internet/sileg/Prop_Detalhe.asp?id=131896 > . Acesso em: 28 jul 2010.

BRASIL. Projeto de Emenda Constitucional no 341 de 2009. Modifica os dispositivos constitucionais retirando do texto matéria que nãoé constitucional. Disponível em: $<$ http:/ /www.camara.gov.br/sileg/Prop_Detalhe.asp?id=427473 >. Acesso em: 10 jul. 2010.

BULOS, Uadi Lammêgo. Curso de direito constitucional. 4 ed. São Paulo: Saraiva, 2009.

CANOTILHO, José Joaquim Gomes. Estudos sobre direitos fundamentais. 2 ed. Coimbra: Coimbra Editores, 2008.

CARVALHO NETTO, Menelick. A constituição da europa. In: SAMPAIO, José Adércio Leite (Coord.) Crise e desafios da constituição: perspectivas críticas da teoria e das práticas constitucionais brasileiras. Belo Horizonte: Del Rey, 2003. p. 281-289.

. A urgente revisão da teoria do poder constituinte: a impossibilidade da democracia possível. In: CATTONI DE OLIVEIRA, Marcelo. Poder constituinte e patriotismo constitucional: o projeto constituinte do estado democrático de direito na teoria discursiva de Jürgen Habermas. Belo Horizonte: Mandamentos, 2006. p. 19-29.

CATTONI DE OLIVEIRA, Marcelo. Poder constituinte e patriotismo constitucional: o projeto constituinte do estado democrático de direito na teoria discursiva de Jürgen Habermas. Belo Horizonte: Mandamentos, 2006.

CRUZ, Álvaro Ricardo de Souza. Breve histórico do supremo tribunal federal e do controle de constitucionalidade brasileiro. In: SAMPAIO, José Adércio Leite (Coord.) Crise e desafios da constituição: perspectivas críticas da teoria e das práticas constitucionais brasileiras. Belo Horizonte: Del Rey, 2003. p. 201-255.

DWORKIN, Ronald. Levando os direitos a sério. Trad. Nelson Boeira. São Paulo: Martins Fontes, 2002.

O império do direito. São Paulo: Martins Fontes, 2003.

FERRAZ JR.,Tércio Sampaio. Função social da dogmática jurídica. São Paulo: Max Limonad, 1998.

HABERMAS, Jürgen. A constelação pós-constitucional: ensaios políticos. Trad. Márcio Seligmann-Silva. São Paulo: Littera Mundi, 2001.

Consciencia moral y acción comunicativa. Trad. Ramón García Cotalero. Barcelona: Península, 1996. 
. Direito e democracia: entre facticidade e validade. Trad. de Flávio Bueno Siebneichler. Rio de Janeiro: Tempo Brasileiro, 1997.

HABERMAS, Jürgen. Teoría de la acción comunicativa: crítica de la razón funcionalista. Trad. Manuel Jiménez Redondo. Madri: Taurus, 2001.

A inclusão do outro: estudos de teoria política. Trad. George Sperber. São Paulo: Loyola, 2002.

Between facts and norms: contributions to a discourse theory of law and democracy. Trad. William Rehg. Cambridge: MIT Press, 1996.

HESSE, Conrad. Escritos de derecho constitucional. Madrid: Centro de Estúdios Constitucionales, 1992. p. 67.

RAMOS, William Junqueira. A inconstitucionalidade do projeto de emenda à constituição federal (pec) $n^{\circ} 157 / 03$, que convoca uma nova assembléia constituinte revisional. Disponível em <http://jus2.uol.com.br/doutrina/texto.aps?id=8093>. Acesso em 03 de jun de 2010.

SARLET, Ingo Wolfgang. Direitos sociais como direitos fundamentais. In: LEITE, George Salomão; SARLET, Ingo Wofgang. (Coord.). Direitos fundamentais e estado constitucional: estudos em homenagem a J.J. Gomes Canotilho. São Paulo: RT, 2009. p. 213-253.

SARMENTO, Daniel. O neoconstitucionalismo no brasil: riscos e possibilidades. In: LEITE, George Salomão; SARLET, Ingo Wofgang. (Coord.). Direitos fundamentais e estado constitucional: estudos em homenagem a J.J. Gomes Canotilho. São Paulo: RT, 2009. p. $09-49$.

SILVA, José Afonso da. Curso de direito constitucional positivo. 22 ed. São Paulo: Malheiros, 2002.

SIMIONI, Rafael Lazzarotto. Direito e racionalidade comunicativa: a teoria discursiva do direito no pensamento de Jürgen Habermas. Curitiba: Juruá, 2007.

SIQUEIRA, Gustavo Silveira. Legitimidade, reforma e democracia na constituição federal de 1988. Florianópolis: CONPEDI, 2007.

STRECK, Lenio Luiz. Uma abordagem hermenêutica acerca do triângulo dialético de canotilho ou de como ainda é válida a tese da constituição dirigente (adequada a países de modernidade tardia. In: LEITE, George Salomão; SARLET, Ingo Wofgang. (Coord.). Direitos fundamentais e estado constitucional: estudos em homenagem a J.J. Gomes Canotilho. São Paulo: RT, 2009. p. 50-78.

STRECK, Lenio Luiz; CATTONI DE OLIVEIRA, Marcelo Andrade; CARVALHO NETTO, Menelick de; LIMA, Martonio Barreto. Revisão é golpe! Porque ser contra a proposta de revisão constitucional. Disponível em: <http://jus2.uol.com.br/doutrina/ texto.aps?id=8093> Acesso em 28 junho 2010.

Assembleia constituinteé golpe! Última instância. Porto Alegre, sexta-feira, 19 de ago. 2005. Disponível em: < http://www.leniostreck.com.br > . Acesso em 09 de ago de 2010. 